\title{
CARA PANDANG UMAT BUDDHA DESA NUSA JAYA, SUMATERA SELATAN DALAM MELAKSANAKAN TRADISI SATU SURO
}

\author{
WIDIYANTO \\ STIAB JINARAKKHITA LAMPUNG \\ wyanto1979@gmail.com
}

\begin{abstract}
Abstrak
Berbagai macam cara yang dilakukan oleh masyarakat di Desa Nusa Jaya dalam memperingati upacara tradisi satu suro yang merupakan tradisi leluhur yang masih dilakukan dan dipegang teguh. Tujuan penelitian adalah untuk mengetahui bagaimana sejarah serta pelaksanaan upacara tradisi satu suro, serta maknanya bila dipandang dari perspektif agama Buddha di desa Nusa Jaya.Berdasarkan data yang diperoleh, jenis penelitian yang digunakan adalah penelitian lapangan (field research). Menurut bidang yang diteliti penelitian yang dilakukan termasuk di dalam jenis penelitian deskriptif kualitatif. Subyek dalam penelitian ini adalah panitia, tokoh agama Buddha, tokoh masyarakat di desa Nusa Jaya, Belitang 3, OKU Timur. Hasil penelitian menunjukkan bahwa: (1) Tradisi satu suro merupakan ritual yang telah mendarah daging untuk masyarakat desa Nusa Jaya. Tradisi satu suro dilaksanakan setiap tanggal tujuh malam kedelapan di bulan Suro. Tradisi ini merupakan Kolaborasi antara Kebudayaan Jawa dan konsep tata ritual agama setempat; (2) Tradisi satu suro ini merupakan rangkaian kebudayaan lokal yang dikolaborasikan dengan kepercayaan agama setempat untuk memperingati Tahun baru Jawa. Tradisi satu suro ini sebagai sarana untuk penghormatan terhadap Leluhur; (3) Bentuk nilai-nilai spiritual tradisi satu suro di desa Nusa Jaya antara lain: Ritual mubeng deso, Membawa persembahan (sesajen), Lek-lekan (tidak tidur semalam), dan Poso (puasa).
\end{abstract}

Kata Kunci: Cara Pandang Umat Buddha, Suro

\begin{abstract}
There are many ways done by society of Nusa Jaya village in celebrating the first Suro (Javanese month) night which is the ancestor's tradition done and held on tight. This study aims to find out how the history of the first Suro ceremony practice is and also to identify its meaning from Buddhist perspective in Nusa Jaya village. Based on the data collected, this study is field research. It also belongs to descriptive qualitative study. The subjects of this study are committees, Buddhist figures, and people of Nusa Jaya, Belitung 3, east OKU. The result of this study shows that (1) first Suro tradition is done every seventh night of eight in Suro. This tradition is the collaboration of Javanese culture and concept of local religious rituals; (2) this tradition is series of local culture collaborated with local religious beliefs as the means of ancestral respect; (3) form of first Suro' s spiritual values in Nusa Jaya village are mubeng deso ritual, bring sesajen (offerings), lek-lekan (stay up late), and poso (fasting)
\end{abstract}

Keywords: Buddhist perspective, Suro 


\section{PENDAHULUAN}

Bulan Suro diyakini sebagai bulan yang keramat dan identik dengan masyarakat jawa. Mengapa demikian? Karena banyak masyarakat jawa yang beranggapan bahwa malam yang sangat sakral. Hal ini dapat dilihat dari begitu kental masyarakat jawa yang merasuk ke dalam nadi kehidupan mereka hingga muncul beragam tradisi, sebagai cerminan kepercayaan mereka. Sebagian masyarakat pada malam satu suro dilarang untuk kemana-mana kecuali untuk berdoa ataupun melakukan ibadah lain. Satu Suro merupakan hari pertama dalam kalender Jawa di bulan suro, dimana bertepatan dengan 1 Muharram dalam kalender hijriyah, karena kalender jawa dari Sultan Agung yang mengacu pada penanggalan Hijriyah (Islam).

Satu suro biasanya diperingati pada malam hari setelah magrib pada hari sebelum tanggal satu biasanya disebut malam satu suro. Hal ini karena pergantian hari Jawa dimulai pada saat matahari terbenam dari hari sebelumnya, bukan pada tengah malam. Tradisi ini merupakan sebuah warisan kebudayaan dari nenek moyang melalui turun- temurun hingga sekarang, khususnya orang jawa, mereka banyak yang memperingati serta meyakini pada bulan Suro sebagai bulan sakral yang kebanyakan mereka gunakan untuk mengharap dan menerima berkah dari bulan suci ini. Selain dianggap bulan sakral, bulan suro juga dijadikan bulan untuk intropeksi diri dari perbuatan yang mereka lakukan selama satu tahun.

Masyarakat Desa Nusa Jaya, Kecamatan Belitang 3, Kabupaten OKU Timur telah memandang bahwa Upacara Tradisi suro yang dilakukan membawa perubahan. Perubahan ini dalam konteks positif tampak dalam aspek keagamaan. Masyarakat semakin sadar akan pentingnya nilai-nilai keagamaan. Perubahan pengalaman keagamaan tersebut dapat dirasakan dengan adanya kedamaian jiwa individu, mereka hidup damai meskipun terdapat beraneka ragam atau macam agama di wilayah tersebut. Aktivitas keagamaan inilah yang pelan tapi pasti akhirnya mengubah pola pikir masyarakat, di samping itu, adanya perbedaan geografis dan iklim akan mempengaruhi lahirnya berbagai masa dan ragam kebudayaan yang menyentuh sistem nilai, sistem simbol, sistem seni maupun sistem pengetahuan manusia.

Dari latar belakang muncul pertanyaan dari peneliti, 1. Bagaimana sejarah dan prosesi pelaksanaan upacara tradisi satu suro di desa Nusa Jaya, OKU Timur? 2. Bagaimana implikasi kepercayaan upacara tradisi satu suro terhadap keyakinan umat Buddha di desa Nusa Jaya, OKU Timur? 3. Bagaimana makna tradisi satu suro menurut perspektif umat Buddha di Nusa Jaya, OKU Timur? Adapun penelitian 
ini bertujuan untuk: 1. Mengetahui sejarah dan pelaksanaan upacara tradisi satu suro di desa Nusa Jaya, OKU Timur. 2. Mengetahui implikasi kepercayaan upacara tradisi satu suro terhadap keyakinan umat Buddha di desa Nusa Jaya, OKU Timur. 3. Mengetahui makna tradisi satu suro menurut perspektif umat Buddha di desa Nusa Jaya, OKU Timur. Selanjutnya penelitian ini diharapkan dapat bermanfaat untuk seluruh masyarakat pada umumnya dalam melestarikan budaya nenek moyang kita, serta bagi umat Buddha pada khususnya agar dapat melakukan dan menjalankan suatu upacara dengan bijaksana.

Kata kepercayaan menurut istilah (terminologi) yaitu keyakinan kepada keTuhanan Yang Maha Esa di luar agama atau tidak termasuk ke dalam agama (Kartapradja, 1985:1). Masyarakat dalam bahasa inggris disebut society (berasal dari kata Latin socius, yang berarti "kawan". Masyarakat berasal dari akar kata Arab syaraka, yang artinya ikut serta atau berperan serta. Jadi, yang dimaksud masyarakat adalah sekumpulan manusia yang saling berinteraksi (Koentjaraningrat, 2003:119-120). Fungsi kepercayaan dapat digunakan sebagai alat untuk melegitimasi atau sebagai alat pembenaran untuk peristiwa-peristiwa tertentu. Kepercayaan merupakan ungkapan simbolik suatu masyarakat dalam menghadapi konflikkonflik yang terjadi. Melalui kepercayaan tersebut, masyarakat belajar terhadap nilainilai moral dan budaya yang terdapat di dalamnya. Kepercayaan sebagai perangkat yang berfungsi sebagai simbol-simbol nasional atau kultural yang membangkitkan kesetiaan yang seragam pada masyarakat, baik secara horizontal lintas wilayah maupun secara vertikal lintas kelas (Anderson, 2008:10).

Tradisi adalah suatu kebiasaan yang telah dilakukan sejak lama dan menjadi bagian dari kehidupan suatu kelompok masyarakat, biasanya dari suatu wilayah, negara, kebudayaan, golongan atau agama yang sama. Masyarakat Jawa memang terkenal dengan beragam jenis tradisi atau budaya yang ada di dalamnya. Baik tradisi kultural yang semuanya ada dalam tradisi atau budaya Jawa tanpa terkecuali. Dari beragam macamnya tradisi yang ada di masyarakat Jawa, hingga sangat sulit untuk mendeteksi serta menjelaskan secara rinci terkait dengan jumlah tradisi kebudayaan yang ada dalam masyarakat Jawa tersebut. Menurut khazanah bahasa Indonesia, tradisi berarti segala sesuatu seperti adat, kebiasaan, ajaran dan sebagainya, yang turun temurun dari nenek moyang. Ada pula yang menginformasikan bahwa tradisi berasal dari kata traditium, yaitu segala sesuatu yang ditransmisikan, diwariskan oleh masa lalu ke masa sekarang. Pada intinya, tradisi merupakan warisan masa lalu yang dilestarikan terus hingga sekarang, 
dapat berupa nilai, norma sosial, pola kelakuan dan adat -kebiasaan lain yang merupakan wujud dari berbagai aspek kehidupan. (Bawani, 1993:87)

Kata "Suro" merupakan sebutan bagi bulan Muharram dalam masyarakat Jawa. Kata tersebut sebenarnya berasal dari kata "asyura" dalam bahasa Arab yang berarti "sepuluh", yakni tanggal 10 bulan Muharram (Sholikhin, 2010). Tanggal 10 bulan Muharram bagi masyarakat Islam memiliki arti yang sangat penting. Memang dasarnya tidak begitu sahih atau kuat, namun itu telah menjadi tradisi bagi masyarakat muslim. Karena pentingnya tanggal itu, oleh masyarakat Islam Indonesia, Jawa utamanya, tanggal itu akhirnya menjadi lebih terkenal dibanding nama bulan Muharram itu sendiri. Yang lebih populer adalah asyura, dan dalam lidah Jawa menjadi "Suro". Jadilah kata "Suro" sebagai khazanah Islam-Jawa asli sebagai nama bulan pertama kalender Islam maupun Jawa. Kata "suro" juga menunjukkan arti penting 10 hari pertama bulan itu dalam sistem kepercayaan Islam-Jawa, di mana dari 29 atau 30 hari bulan Muharram, yang dianggap paling "keramat" adalah 10 hari pertama, atau lebih tepatnya sejak tanggal 1 sampai 8 , saat mana dilaksanakan acara kenduri bubur Suro. Namun mengenai kekeramatan bulan Suro bagi masyarakat Islam-Jawa, lebih disebabkan oleh faktor atau pengaruh budaya keraton, bukan karena "kesangaran" bulan itu sendiri. (Sholikhin, 2010:83-84)

\section{METODE}

Penelitian ini adalah penelitian lapangan (field research) dengan pendekatan kualitatif deskriptif yang mengambil fokus kajian pada upacara tradisi satu suro dalam sudut pandang umat Buddha di desa Nusa Jaya, OKU Timur sebagai media dari budaya dan agama yang bertujuan untuk mengkaji bagaimana kepercayaan umat Buddha terhadap upacara tersebut, serta mengungkap fungsi, tujuan dan faktor-faktor yang menjadikannya tradisi.

Sumber penelitian diperoleh dari sumber data primer dan sumber data sekunder. Sumber data primer, yaitu sumber data yang memberikan data secara langsung dalam penelitian ini. Adapun yang dimaksud sebagai sumber data primer yaitu tokoh agama, masyarakat atau sebagian penduduk desa Nusa Jaya, OKU Timur yang mengerti dan paham terhadap prosesi Suronan sebagai responden atau obyek penelitian ini. Sumber data sekunder, yaitu sumber tambahan atau sumber pendukung yang juga berkaitan dengan penelitian tersebut. Data ini diperoleh dari buku ataupun literatur yang terkait dengan tema penelitian tersebut.

Subjek / informan dalam penelitian ini adalah: 1. Ketua panitia pelaksana suronan. Peneliti memilih ketua panitia karena dianggap mengetahui dengan baik bagaimana proses pelaksanaan dan upacara 
suronan yang dilaksanakan di desa Nusa Jaya. 2. Tokoh agama. Peneliti memilih tokoh agama yang ada di desa Nusa Jaya karena mereka juga sebagai praktisi dalam upacara suronan dan sekaligus mengetahui kaitannya suronan bila dikaitkan dengan agama Buddha. 3. Sebagian penduduk desa Nusa Jaya, OKU Timur yang mengikuti upacara tradisi satu suro dari awal sampai akhir, karena secara otomatis minimal mengetahui apa yang dilakukan selama mengikuti upacara. Pemilihan informan yang dijadikan sebagai informan adalah sengaja ditunjuk oleh peneliti dengan alasan memiliki pengetahuan yang luas sesuai dengan judul penelitian

\section{PEMBAHASAN}

\section{TEMUAN PENELITIAN}

Kelurahan Nusa Jaya berdiri berdasarkan surat keputusan Gubernur Sumatera Selatan nomor: GB/100/B.1/Hk/1961, tanggal 1 Januari 1961 yang mana penduduk desa Nusa Jaya merupakan transmigran berasal dari pulau Jawa yang berjumlah 250 kepala keluarga (KK) dengan jumlah penduduk sebanyak 742 pada awalnya.

Table 1. Jumlah penduduk di desa Nusa Jaya Februari 1961

\begin{tabular}{|c|c|c|c|c|}
\hline No & Agama & L & P & Jumlah \\
\hline 1. & Islam & 321 & 320 & 641 \\
\hline 2. & Katolik & 30 & 15 & 45 \\
\hline 3. & Buddha & 20 & 10 & 30 \\
\hline 4. & Protestan & 12 & 14 & 26 \\
\hline & Total & 383 & 359 & 742 \\
\hline
\end{tabular}

Table 2. Jumlah penduduk di desa Nusa Jaya Januari 2019

\begin{tabular}{|c|c|c|c|c|}
\hline No & Agama & L & P & Jumlah \\
\hline 1. & Islam & 623 & 621 & 1244 \\
\hline 2. & Katolik & 159 & 151 & 310 \\
\hline 3. & Buddha & 71 & 67 & 138 \\
\hline 4. & Protestan & 12 & 13 & 26 \\
\hline & Total & 383 & 359 & 1718 \\
\hline
\end{tabular}

Desa Nusa Jaya sebelah Utara berbatasan dengan desa Nusa Raya, Sebelah Selatan berbatasan dengan desa Nusa Tenggara, Sebelah Timur berbatasan dengan desa Nusa Bakti, Sebelah Barat berbatasan dengan desa Nusa Agung. Sedangkan untuk luas tanah yang ada di desa Nusa Jaya secara keseluruhan berjumlah $\pm 681 \mathrm{Ha}$, yang terdiri dari jenis tanah pekarangan, perkebunan, persawahan dan pemakaman.

\section{PEMBAHASAN}

Pada kalangan masyarakat Desa Nusa Jaya ada suatu kebiasaan yang kuat dan telah menjadi tradisi, sehingga memiliki nilai sejarah yang cukup unik dan menarik untuk diabadikan yaitu upacara tradisi Satu Suro. Masyarakat sering menyebutnya tradisi suran atau suronan.

Upacara adat suronan merupakan suatu jenis budaya tradisional yang bersifat kejawen dan kental dengan hal-hal yang berbau mistik. Wawancara penulis dengan Bapak Sup (Tokoh Agama Buddha), dikatakan bahwa tradisi satu suro atau sering disebut suran/suronan, adalah ritual yang dilaksanakan oleh masyarakat terutama masyarakat desa Nusa Jaya untuk memperingati datangnya bulan 
Suro/Muharram serta mengucapkan rasa syukur kepada Tuhan atas segala rahmat yang diberikan. Upacara adat Satu Suro sendiri sudah lama sekali dilaksanakan, bahkan semenjak beliau sendiri belum lahir, hanya saja prinsip mereka semata-mata hanya mewarisi adat dan tradisi dari nenek moyangnya yang mereka anggap tidak bisa ditinggalkan apalagi dilupakan.

Salah satu ciri dari masyarakat Jawa adalah adanya tradisi selamatan (mengadakan selamatan, kenduri). Ini merupakan ritual keagamaan yang paling umum dilakukan, yang melambangkan persatuan mistik dan sosial dari orang-orang yang ikut serta dalam selamatan itu. Selamatan dan lambang-lambang yang mengiringinya memberikan gambaran yang jelas tentang tata cara perpaduan antara ritual-ritual yang terdapat dalam agama Buddha yang membentuk nilai pokok masyarakat pedesaan. Selamatan diadakan pada hampir setiap kesempatan yang mempunyai arti upacara selingkaran hidup, seperti kehamilan, kelahiran, pengkhitanan, perkawinan, kematian, hari raya keagamaan resmi, seperti lebaran, muludan, waisak, nyepi, galungan, upacara panen, dan sebagainya. Jika seseorang ingin merayakan atau mengeramatkan peristiwa apapun yang berhubungan dengan upacara perseorangan atau jika ia hendak meminta berkah atau minta terlindungi dari bencana, maka selamatan harus diadakan.
Tujuan utama selamatan adalah mengupayakan keadaan slamet (selamat), dalam arti tidak terganggu oleh kesulitan alamiah atau gangguan gaib. Selamatan bukan meminta kekayaan, tetapi upacara untuk menjaga agar tidak terjadi sesuatu yang dapat membingungkan atau menyedihkan, yang memiskinkan atau yang mendatangkan penyakit. Juga agar orang tersebut terhindar dari perasaan hendak menyerang orang lain, atau dari gangguan emosional.

Tujuan diadakannya upacara tradisi suronan Desa Nusa Jaya Kec. Belitang 3 yaitu:

1. Untuk melestarikan tradisi peninggalan nenek moyang desa Nusa Jaya dan dalam rangka perayaan atau sukuran datangnya tahun baru, dalam hal ini adalah kalender Jawa.

2. Untuk mewujudkan keselamatan dan ketentraman masyarakat desa Nusa Jaya dengan harapan agar tahun berikutnya lebih baik dari tahun sebelumnya.

3. Untuk mewujudkan rasa syukur kepada Tuhan yang telah melimpahkan anugerah, karunia dan rejeki bagi masyarakat, mengembangkan persatuan, kesatuan, keharmonisan, kesejahteraan, keadilan dan kemakmuran bagi semua yang melaksanakan tradisi tersebut, tanpa ada pertengkaran dan perselisihan, serta saling menghormati. Masyarakat Desa Nusa Jaya, Kec. Belitang 3 meyakini sepanjang bulan 
Suro untuk terus bersikap eling (ingat) dan waspodo (waspada).

Pada pelaksanaan Upacara Tradisi Satu Suro di Desa Nusa Jaya, Kecamatan Belitang 3 memiliki beberapa tradisi yang dilaksanakan sejak lama dan berlangsung secara kontinyu atau berkelanjutan. Adapun Uraiannya adalah sebagai berikut:

\section{Mubeng deso (berkeliling dengan membacakan doa) \\ Pada dasarnya suronan} diselenggarakan pada malam menyambut 1 Suro, tetapi suronan di desa Nusa Jaya dilaksanakan seminggu setelah 1 suro, yaitu pada malam ke- 8 bulan suro. Setelah warga berkumpul maka diadakannya doa bersama. Berdasarkan hasil wawancara dengan panitia: "Bahwa di dalam acara mengelilingi desa diselipkan pembacaan doa bersama yang dipimpin oleh masing-masing tokoh agama, untuk meminta keselamatan dan keberkahan pada tahun baru nanti agar tidak mendapat kesialan. Doa-doa ini dimaksudkan agar masyarakat Desa Nusa Jaya dapat diberi keberkahan, kesejahteraan, kemakmuran dalam kehidupan di awal tahun baru Suro/Muharram, mereka menganggap bahwa jika tidak memanjatkan doa akan mendapat kesialan.

Ritual Mubeng deso kalau dalam Buddhis hampir sama dengan Pradaksina, akan tetapi ritual Mubeng deso di sini dalam tradisi suronan tidak sama dengan pradaksina yang dilakukan pada peringatan waisak yaitu dengan searah jarum jam melainkan berlawanan jarum jam, itu bertujuan melawan mara bahaya. Pradaksina berasal dari kata Padakkhina yang berasal dari bahasa Pali. Dalam bahasa sansekerta, istilah Pradaksina terbagi dalam dua kata yakni Pra yang berarti ke depan dan daksina berarti kanan atau selatan.

Pradaksina merupakan salah satu aktivitas Puja Bhakti dalam agama Buddha. Dalam arti luas, Pradaksina adalah suatu sikap mempersiapkan batin dalam melaksanakan Puja Bakti dengan cara berjalan mengelilingi suatu objek dari arah kiri lalu ke kanan atau dari arah timur ke barat searah jarum jam sebanyak 3 kali putaran. Penyebutan Pradaksina sering kali diucapkan dalam berbagai macam seperti Pradaksina, Padakhina, Purwadaksina. Hal ini dikarenakan setiap wilayah penyebaran Puja Bhakti Pradaksina ini berbeda. Pada masa Buddha Gautama menyebarkan salah satu ajarannya yakni Dharma setelah mencapai penerangan agung, datanglah muridnya bernama Brahma Sahampati dengan berjalan mengelilingi Buddha Gautama yang saat itu sedang duduk dibawah pohon Bodhi. Pohon Bodhi ini selanjutnya dijadikan sebagai simbol pencapaian penerangan agung Buddha dari masa meditasi sampai mencapai ke-Buddha-an (mencapai pandangan terang). Brahma Sahampati melakukan hal tersebut dianggapnya sebagai penghormatan kepada Sang Guru sebanyak 3 kali putaran searah 
jarum jam. Sikap Brahma Sahampati ini kemudian diulang kembali oleh para murid Buddha Gautama yang dijadikan sebagai ritual untuk menghormatinya.

Dalam perkembangannya, ritual Pradaksina dilakukan dengan berbagai macam persepsi orang yang memahaminya. Pada tahun 483 SM di kerajaan Kusinara, Buddha Gautama meninggal. Saat Buddha Parinibbana (mencapai penerangan sempurna), selama tujuh hari tujuh malam jenazahnya dikunjungi raja dan semua lapisan masyarakat. Salah satu murid teladannya yakni Yang Arya Maha Kassapa melakukan penghormatan terakhir untuk Buddha Gautama dengan membaca parritaparrita (mantra yang berkaitan dengan ajaran Dhamma) disertai dengan mengelilingi tubuh Buddha seperti yang dilakukan oleh Brahma Sahampati. Saat inilah wujud penghormatan pada Buddha yang berupa Puja Bakti dengan membaca parrita dan Pradaksina lahir.

Konsep Pradaksina mempunyai filosofi yang berkaitan dengan pergerakan matahari. Selain itu Pradaksina juga identik dengan perputaran jarum jam yang searah, hal ini juga dipengaruhi oleh filosofi pergerakan matahari. Filosofi Pradaksina ini biasa dimaknai sebagai sesuatu yang positif dan menuju ke arah masa depan yang lebih baik. Sebaliknya jika sesuatu hal yang berlawanan dengan arah jarum jam, akan dimaknai sebagai hal negatif dan membawa keburukan. Pandangan konsep filosofi Pradaksina ini telah dibawa oleh Bangsa Aria menjadi pergerakan matahari sebagai simbol Swastika. Swastika ini adalah keberuntungan yang mengandung makna Dharma, keharmonisan universal serta keseimbangan. Selain itu, ditemukan hal menarik dalam simbol Swastika yang dikenal oleh India Utara sebagai Pradaksina dan di Jerman sebagai simbol gerakan Nazi pada Perang Dunia II.

\section{Tradisi Kenduri/Kenduren atau bersedekah}

Pada pukul 21.00 sampai selesai, Setelah acara mubeng deso, doa bersama selesai maka warga melanjutkan dengan acara makan bersama atau kenduri dalam memperingati satu suro. Kenduri, dilakukan sebagai bentuk rasa syukur, sebuah penghormatan, do'a, atau bisa disebut juga selamatan yang dilakukan dalam hal-hal tertentu, biasanya untuk hajatan tertentu, Dalam hal ini kenduri diadakan bertepatan dengan satu suro dengan tujuan meminta keberkahan, keselamatan pada warga Desa Nusa Jaya. Makanan yang dihidangkan saat kenduri, yaitu bubur merah putih, beberapa nasi tumpeng, lauk pauk yang lainnya dan berbagai makanan ringan seperti (berbagai panganan khas desa seperti lemper, jadah, wajik, jenang, ungkusan dan teh/kopi panas). Kemudian ada besek/takir (kotak yang terbuat dari bambu yang dianyam atau daun pisang) atau sekarang diganti tempat dari plastik, besek/takir tersebut diisi nasi 
(biasanya nasi uduk/nasi gurih) dengan lauk pauk beragam, seperti mie, jangan lombok (sayur kentang, krecek sapi, dicampur irisan cabe yang dimasak dengan santan kental), tempe goreng, telur rebus, rempeyek ditambah bermacam-macam makanan kecil.

Dalam agama Buddha dikenal dengan Amisa Puja yang berarti pemujaan dengan persembahan seperti rupang, lilin, dupa, bunga dan buah-buahan. Makna Amisa Puja secara harafiah berarti pemujaan dengan persembahan. Kitab Mangalatthadipani menguraikan empat hal yang perlu diperhatikan dalam menerapkan Amisa Puja ini, yaitu: Sakkara: memberikan persembahan materi, Garukara: menaruh kasih serta bakti terhadap nilai-nilai luhur, Manana: memperlihatkan rasa percaya/yakin, Vandana: menguncarkan ungkapan atau kata persanjungan.

Selain itu, ada tiga hal lagi yang juga harus diperhatikan agar Amisa Puja dapat diterapkan dengan sebaik-baiknya. Ketiga hal tersebut yaitu :

a. Vatthu sampada: kesempurnaan materi

b.Cetana sampada: kesempurnaan dalam kehendak

c. Dakkhineyya sampada: kesempurnaan dalam obyek pemujaan

Sejarah Amisa puja menurut dilaksanakan bermula dari bhikkhu Ananda. Beliau adalah murid setia Sang Buddha, setiap hari mengatur tempat tidur, membersihkan tempat tinggal, membakar dupa, menata bunga dll, mengatur pergiliran umat untuk menemui atau menyampaikan dana makanan kepada Buddha. Setelah Buddha parinibbana, para arahat tidak terguncang batin-nya, tetapi Bhikkhu Ananda yang belum mencapai arahat, masih merasakan sedih dan berduka, karena selama bertahuntahun ia berada di dekat Buddha, untuk merawat dan melayani. Kebiasaan menyiapkan cendana, bunga-bungaan dan lain-lain yang dilakukan oleh Bhikkhu Ananda kepada Buddha inilah yang menjadi kebiasaan umat Buddha melaksanakan amisa puja sampai sekarang. Umat Buddha melaksanakan amisa puja pada altar, relik orang suci, termasuk kepada para Bhikkhu dengan memberikan dupa, bunga, lilin, dan lain-lain.

\section{Lek-lekan (tidak tidur semalaman suntuk)}

Lek-lekan (Tidak tidur semalam suntuk) adalah tradisi yang biasanya dilakukan oleh warga desa Nusa Jaya setelah melakukan acara mubeng desa. Sebagian besar masyarakat mempercayai pada malam satu suro muncul kekuatan gaib atau kekuatan yang tidak tampak oleh mata telanjang.

Kegiatan Lek-kan disini dalam pandangan agama Buddha bisa diisi dengan melakukan Meditasi (Bhavana). Tujuan meditasi adalah memusatkan pikiran dan menenangkan pikiran. Dari pembagian kelompok Jalan Mulia Berunsur Delapan, konsentrasi benar menjadi salah satu bagian 
yang tidak dapat dipisahkan dengan perhatian benar. Latihan konsentrasi pada awalnya dilakukan dengan memusatkan pikiran pada objek meditasi yang telah ditentukan.

Pencapaian tertinggi meditasi konsentrasi (Samatha Bhavana) ini disebut dengan Jhana. Apabila tingkat konsentrasi ini dapat dicapai, maka pelaku meditasi dapat melanjutkan dengan mengembangkan kesadaran pada segala gerak gerik pikiran maupun badan. Latihan meditasi tingkat lanjutan ini disebut sebagai meditasi mengembangkan kesadaran (Vipassana Bhavana) yang hasil tertingginya adalah kebijaksanaan (Panña). Untuk mencapai kebijaksanaan sebagai hasil latihan pengendalian pikiran secara maksimal, diperlukan beberapa persiapan dasar. Seperti diketahui bahwa pikiran adalah merupakan bagian dari batin, sedangkan manusia terdiri dari badan serta batin, maka persiapan badan yang baik akan mendukung perkembangan kualitas batin yang baik pula. Persiapan badan dimulai dengan memahami posisi badan yang ideal selama bermeditasi. Ada empat posisi meditasi yang dapat dipergunakan yaitu duduk, berdiri, berjalan serta berbaring.

Posisi duduk biasanya dilakukan dengan bersila, yaitu menyilangkan kedua kaki. Idealnya, kedua kaki dilipat sedemikian rupa sehingga kedua telapak kaki terletak di atas paha. Jadi, telapak kaki kiri berada di atas paha kanan dan telapak kaki kanan terletak di atas paha kiri. Namun, kalau sulit untuk melakukan posisi ini, boleh juga kaki kiri dilipat dan diletakkan di bawah kaki kanan. Telapak kaki kanan berada di atas paha kiri. Akan tetapi, jika posisi ini pun sulit dilakukan, pergunakan posisi apapun juga yang penting duduk bisa terasa nyaman tanpa diganggu rasa kesemutan untuk waktu meditasi yang telah ditentukan, misalnya 15 atau 30 menit tanpa bergerak. Setelah mampu memposisikan kaki sehingga nyaman duduk, maka letakkan kedua telapak tangan berada di pangkuan. Telapak tangan kiri berada di bawah telapak tangan kanan. Biasanya, kedua ujung ibu jari dipertemukan. Duduklah dengan tegak namun santai. Kepala tegak, mata dipejamkan, dan bernafaslah secara normal. Pusatkan pikiran pada obyek meditasi yang telah dipilih. Apabila pikiran memikirkan hal lain, sadarilah dan segera pusatkan kembali pada obyek meditasi tersebut. Demikian seterusnya selama waktu meditasi yang telah ditentukan.

Adapun meditasi dengan posisi berdiri dilakukan sesuai namanya yaitu memusatkan pikiran sambil berdiri tegak. Agar seseorang mampu berdiri secara nyaman, posisikan kedua telapak kaki satu sama lain berjarak selebar pundak. Tangan biasanya diletakkan di bawah pusar, telapak tangan kiri menempel di badan dan telapak tangan kanan di atas punggung tangan kiri. 
Tentu saja tangan boleh diposisikan di tempat lain, misalnya di samping badan, bersilang tangan di depan dada bahkan bersilang tangan di pinggang. Posisikan tangan senyaman mungkin sehingga selama waktu berdiri yang telah ditentukan, konsentrasi tidak terganggu. Kedua mata dipejamkan dan seluruh perhatian dipusatkan pada obyek meditasi.

Posisi meditasi yang lain adalah berjalan. Posisi tangan tetap di bawah perut, atau mungkin di samping badan, bersilang di depan dada ataupun di pinggang. Secara perlahan namun penuh konsentrasi, langkahkan kaki satu demi satu. Pada saat melangkah, seluruh perhatian dipusatkan pada obyek meditasi yaitu, biasanya, proses berjalan atau telapak kaki yang sedang melangkah. Perhatian pada proses berjalan dilakukan dengan merasakan saat kaki diangkat, maju dan diletakkan. Perhatian pada telapak kaki dilakukan dengan menyadari bagian belakang, tengah serta depan telapak kaki yang diangkat dan diletakkan. Meditasi berjalan ini dilakukan di tempat yang lurus dan rata. Jarak yang dipergunakan sekitar 15 langkah sampai dengan 25 langkah. Pelaku meditasi berjalan perlahan sampai di ujung jalan kemudian berbalik dan berjalan kembali sampai di ujung jalan yang lain. Demikian seterusnya sampai selesai waktu meditasi yang ditentukan. Jika kekuatan konsentrasi semakin tinggi, langkah yang dilakukan juga akan semakin perlahan. Ada kemungkinan, jarak sejauh 25 langkah tersebut ditempuh dalam waktu 30 menit atau lebih. Satu langkah mungkin menjadi dua menit atau lebih karena pikiran terpusat sangat kuat memperhatikan kaki yang sedang bergerak.

Sedangkan posisi meditasi yang keempat adalah berbaring. Posisi ini perlu dibedakan dengan tiduran. Tiduran dilakukan dengan tubuh terlentang, tengkurap ataupun menyamping, kepala di atas bantal. Sedangkan posisi meditasi berbaring dilakukan dengan tubuh menyamping ke sebelah kanan, kepala ditopang oleh tangan kanan. Tangan kiri terletak di atas sisi kiri badan. Kaki kiri terletak di atas kaki kanan. Kedua mata dipejamkan. Seluruh perhatian dipusatkan pada obyek meditasi yang telah dipilih.

Meditasi sebaiknya dilakukan pada waktu dan tempat yang sama. Biasanya orang berlatih meditasi pada saat ia bangun tidur dan akan tidur. Lama meditasi, paling sedikit 15 menit sampai dengan 60 menit atau lebih. Lakukan meditasi sesuai dengan kemampuan. Sebelum meditasi, boleh saja melakukan sedikit upacara ritual menurut keyakinan masing-masing. Umat Buddha biasanya melakukan pembacaan paritta atau mengulang kotbah Sang Buddha sekitar 15 sampai 20 menit. Upacara ritual ini diperlukan agar pikiran lebih terarah pada kegiatan spiritual daripada kegiatan material. 


\section{Poso (puasa) melatih diri menahan hawa nafsu}

Poso atau puasa, orang-orang sebelum mengalami perkembangan zaman dulu mereka melakukan poso mutih tidak makan yang mengandung garam. Dalam perkembangannya saat ini beberapa masyarakat melakukan puasa dengan tujuan untuk menahan hawa nafsu.

Dalam pandangan agama Buddha disebut dengan Atthasila, yaitu melakukan puasa dengan tidak makan mulai dari sore hari sampai tengah hari keesokan harinya, tetapi masih bisa minum air. Tujuannya untuk melatih diri mengendalikan hawa nafsu. Puasa ini mempunyai makna Pengendalian diri, dan melakukan perbuatan baik dan benar.

Seperti halnya dalam ajaran agama lain, dalam agama Buddha pun ada ajaran yang mengajarkan umat Buddha untuk berlatih puasa (Atthhasīla). Hal ini dijelaskan Sang Buddha dalam Uposatha Sutta dari Añguttara Nikāya. Dhammika Sutta dari Sutta Nipāta juga memuat penjelasan Sang Buddha kepada Upasaka Dhammika dan 500 temannya tentang pelaksanaan puasa Buddhis ini. Dalam sutta-sutta ini dijelaskan bahwa pelaksanaan puasa cara Buddhis dilakukan pada hari ke-8 paruh bulan, hari ke-14, dan hari ke-15.

Kisah dalam Anguttara Nikāya diceritakan bahwa pada tanggal 8 paruh bulan (atthami), para pembantu dewa
Cātumahārājika melanglang buana untuk melihat apakah pada hari itu manusiamanusia di bumi ini melakukan kebajikan atau tidak? Pada tanggal 14 paruh bulan (catudasi) putra-putra dewa Cātumahārājika melakukan hal yang sama, dan pada tanggal 15

(pannarasi), dewa-dewa Cātummahārājika sendiri yang melakukan hal tersebut. Hasil temuan dari melanglang buana ini dilaporkan dalam persidangan para dewa di alam surga Tâvatimsa.

Dalam perkembangan selanjutnya, pelaksanaan puasa cara agama Buddha ini sering dilakukan pada tanggal 1, 8, 15 dan 23 menurut perhitungan hari berdasarkan peredaran bulan (candrasangkala/imlek). Tanggal 1, 8, 15 dan 23 inilah yang dalam istilah Buddhis sekarang ini dimaksudkan dengan Hari Uposatha. Pada hari uposatha, tanggal 1 dan 15 penanggalan bulan, para Bhikkhu melakukan upacara parisuddho, pengakuan kesalahan terhadap pelanggaran yang dilakukan dan dilanjutkan dengan pengulangan Patimokkha Sìla, baik secara lengkap (227 Sīla) ataupun sebagian. Khusus pada saat satu hari menjelang uposatha bulan terang, tanggal 14 paruh bulan para Bhikkhu dalam tradisi Theravāda Dhammayuttika melakukan cukur rambut.

Istilah Uposatha dapat diartikan sebagai berdiam dalam keluhuran (di vihāra), dalam arti kata pada saat hari uposatha tiba para umat Buddha diharapkan melakukan beberapa kebajikan, seperti: 
menjunjung orangtua, menghormati para petapa dan brahmana, mengikuti puja bakti, bermeditasi, mendengarkan dan mendiskusikan Dhamma, dan melaksanakan delapan sīla (uposathaAtṭhasīla/uposathasīla). Uposathasīla atau Atțhasīla/ațthaingasīla dapat pula disebut pula dengan ațthaingasamannagāta atau delapan sīla yang juga dilaksanakan oleh para petapa. Delapan sila menurut antara lain:

a.Pānātipātā veramaṇ̄ sikkhāpadam samādiyāmi, saya bertekad untuk melatih diri menghindari pembunuhan makhluk hidup.

\section{b.Adinnādānā veramaṇ̄ sikkhāpadam} samādiyāmi, saya bertekad untuk melatih diri menghindari pengambilan barang yang tidak diberikan.

c.Abrahmacariyā veramaṇi sikkhāpadam samādiyāmi, saya bertekad untuk melatih diri menghindari perbuatan tidak suci.

\section{d.Musāvādā veramaṇ̄ sikkhāpadam}

samādiyāmi, saya bertekad untuk melatih diri menghindari ucapan bohong.

\section{e.Surā-meraya-majja-pamādatțhānā}

veraman̄i sikkhāpadaì samādiyāmi, saya bertekad untuk melatih diri menghindari minuman keras, barang yang memabukkan, yang menyebabkan lemahnya kesadaran.

\section{f.Vikāla-bhojanā veramaṇī sikkhāpadam} samādiyāmi, saya bertekad untuk melatih diri menghindari makan makanan setelah tengah hari.
g.Naccagīta-vādita-visūkadassanā-

mālāgandha-vilepana-dhāraṇa-maṇdanavibhūsanațthānā veramaṇ̄ sikkhāpadam samādiyāmi, saya bertekad untuk melatih diri menghindari menari, menyanyi, bermain musik, dan pergi melihat pertunjukan; memakai kalungan bunga, wangi-wangian, dan kosmetik dengan tujuan menghias diri.

\section{h.Uccāsayana-mahāsayanā veramaṇī} sikkhāpadaì samādiyāmi, saya bertekad untuk melatih diri menghindari tempat tidur dan tempat duduk yang tinggi dan mewah.

Inilah delapan sīla yang terdapat dalam diri seorang samana, delapan sīla yang juga dilaksanakan oleh para Arahat sepanjang sisa hidup mereka sebagai orang suci yang bebas dari kekotoran batin. Melatih diri melaksanakan delapan sila ini bukan didasari oleh rasa takut akan hukuman para dewa, bukan pula karena ingin menyenangkan hati para dewa.

Kisah dalam Dīgha Nikāya dijelaskan bahwa: esensi dari uposatha adalah menilai atau mengoreksi diri sehingga menjadi suatu kebiasaan; mampu menahan diri, menghindari hal-hal yang tidak baik, dan menekan atau memadamkan apa yang jahat, sedangkan dalam Arguttara Nikāya memberikan keterangan yang jelas tentang pahala dari pelaksanaan kebajikan ini; "apabila hari uposatha dipatuhi dengan pelaksanaan delapan sīla, maka pahalanya sangat besar, sangat menggetarkan kalbu, kelak sekalipun belum berhasil mencapai 
Nibbāna, orang-orang yang memiliki kebajikan uposathasīla akan terlahir kembali di alam surga".

\section{PENUTUP}

Pelaksanaan Tradisi satu suro dilaksanakan setiap tanggal tujuh malam kedelapan di bulan suro, karena pada malam satu suro, para sesepuh dan pemuka agama desa Nusa Jaya melaksanakan upacara di desa Batu Kebayan, Kec. Liwa, Lampung Barat. Tradisi satu suro merupakan wujud bakti atau penghormatan kepada leluhur dengan cara berjalan mengelilingi desa dengan berlawanan arah jarum jam, dengan membawa persembahan yang dibawa oleh seluruh warga desa untuk didoakan secara bersama-sama oleh semua pemuka agama yang ada, kemudian dibagikan kepada seluruh warga yang hadir pada upacara ritual. Kemudian acara dilanjutkan dengan tidak tidur semalaman dan diisi dengan menenangkan pikiran serta mengendalikan diri dari hal-hal yang negatif.

Bentuk nilai-nilai spiritual tradisi satu suro dalam perspektif agama Buddha di desa Nusa Jaya.

1. Ritual Mubeng deso, sebagai bentuk perenungan untuk selalu intropeksi diri. Dalam pandangan Buddhis hampir mirip dengan Pradaksina.

2. Membawa persembahan atau sesajen bermaksud wujud rasa syukur terhadap alam dan penghormatan dengan leluhur. Dalam Buddhis dikenal dengan Amisa Puja.
3. Lel-lekan (tidak tidur) bermaksud memusatkan pikiran dan menenangkan pikiran. Dalam Buddhis dikenal dengan Meditasi.

4. Poso bermaksud pegendalian diri dan melakukan perbuatan baik. Dalam Buddhis dikenal dengan Atthasila.

Berdasarkan hasil penelitian dan simpulan yang telah diuraikan diatas, maka diajukan beberapa saran yang diharapkan dapat menjadi pertimbangan dalam rangka mengembangkan aktivitas spiritual, agar makna dari upacara yang dilakukan dapat terjaga dan dapat dipahami untuk generasi selanjutnya.

2. Kepada warga umat Buddha desa Nusa Jaya diharapkan dapat membina kerukunan antar warga, melestarikan warisan leluhur dan saling menjaga keharmonisan dalam apapun kegiatan yang dilakukan, agar tercipta masyarakat yang rukun, damai dan sentosa.

Bagi masyarakat umum agar dapat memiliki pemahaman baru tentang upacara tradisi satu suro yang dilakukan oleh warga desa Nusa Jaya sebagai pengetahuan yang dapat menjadi sumber referensi untuk melakukan kegiatan yang sama.

\section{DAFTAR PUSTAKA}

A'mala, Hesti Nur. (2018). "Studi Tentang Ritual Pradaksina Di Maha Vihara Mojopahit Desa Bejijong Trowulan Mojokerto." $\quad$ FAKULTAS USHULUDDIN DAN FILSAFAT UNIVERSITAS ISLAM NEGERI SUNAN AMPEL SURABAYA. 
Ahimsa-Putra, Heddy Shri. (2006). "Strukturalisme Levi-Strauss: Mitos Dan Karya Sastra." Yogyakarta: Galang Press. Retrieved December 25, 2020 (https://www.goodreads.com/book/sho w/2092094.Strukturalisme Levi Strau ss).

Aisyiyah, Fitra Prihantina Nur. (2008). "Tradisi Suronan Di Dusun Tutup Ngisor Desa Sumber Kecamatan Dukun Kabupaten Magelang." UIN Sunan Kalijaga Yogyakarta. Retrieved December 14, 2020 (http://digilib.uinsuka.ac.id/2536/).

Bodhi, Bhikkhu. (2012). “Añguttara Nikāya Khotbah-Khotbah Numerikal Sang Buddha." DhammaCitta Press. Retrieved December 11, 2020 (https://pustaka.dhammacitta.org/eboo k/theravada/Anguttara Nikaya Jilid 4.pdf).

Dhammiko, Bhikkhu. (2020). "Puasa Ala Buddhis." Dhammacakka Online. Retrieved November 28, 2020 (https://dhammacakka.org/?channel=c eramah\&mode $=$ detailbd\&id=404).

Eriyani, Tri. (2009). "Tradisi Satu Suro Di Desa Traji, Kabupaten Temanggung." UIN Sunan Kalijaga Yogyakarta. Retrieved December 14, 2020 (http://digilib.uin-suka.ac.id/2036/).

Fauzi, Maskhun. (2009). "Upacara Tradisi Suronan Mbah Demang Di Desa Banyuraden, Gamping, Sleman, Yogyakarta." UIN Sunan Kalijaga Yogyakarta. Retrieved December 14, 2020 (http://digilib.uinsuka.ac.id/2535/).

Herdiansyah, H. (2012). "Metodologi Kualitatif Untuk Ilmu-Ilmu Sosial." Jakarta: Salemba Humanika.

Kartono, K. (1996). "Pengantar Metode Dan Riset Sosial." Manjar Maju, Bandung.

Muhadjir, Noeng. 2000. "Metodologi Penelitian Kualitatif." Yogyakarta Rake Sarasin. Retrieved December 12, 2020

(https://onesearch.id/Record/IOS2863. JATEN000000000132825).
Paramita, Rosalina Desi. (2020). "Nilai Spiritual Tradisi Bakti Marga Dalam Perspektif Buddhis." Jurnal Pariwisata Dan Budaya 1.

Rodjali, Selamat. (2007). "Upacara Dalam Agama Buddha." Dhamma Study Group Bogor. Retrieved November 28, 2020 (https://samaggiphala.or.id/naskah-dhamma/upacaradalam-agama-buddha/).

Sholikhin, M. (2010). Misteri Bulan Suro: Perspektif Islam Jawa. books.google.com.

Subagyo, P. J. (1991). Metode Penelitian: Dalam Teori Dan Praktek. Rineka Cipta.

Susilo, Agus. (2017). "Tolerance of Religious People in Nusa Jaya Villages, District III of Belitang, South East Regency, South Sumatera Province." Yupa: Historical Studies Journal 1.

Tim Dapodikbud. (2018). "Nusa Jaya, Nusa Jaya, Kec. Belitang III, Kab. Ogan Komering Ulu Timur Prov. Sumatera Selatan." Retrieved December 11, 2020

(http://sekolah.data.kemdikbud.go.id/i ndex.php/chome/profil/D0C15C952BF5-E011-8CD4-6BB7A374DF26/).

Uttamo, Bhikkhu. (2018). "Dasar-Dasar Meditasi." Vihara Bodhigiri. Retrieved November 28, 2020 (https://bodhigiri.com/bodhigiri/dasardasar-meditasi/).

Walshe, Maurice. (2009). "KhotbahKhotbah Panjang Sang Buddha Dãgha Nikàya." Team DhammaCitta Press. Retrieved December 11, 2020 (https://pustaka.dhammacitta.org/eboo k/theravada/Digha Nikaya - KhotbahKhotbah Panjang Sang Buddha.pdf). 